\title{
Creative
}

\section{Quantum Notes on Classic Places}

\section{Diego Segatto}

Independent researcher, Bologna 40125, Italy; diego.segatto@gmail.com

Received: 7 July 2017; Accepted: 21 July 2017; Published: 31 July 2017

I would like to sing about an unstable, yet constant force that stresses and pushes imagination. It makes cultural and social transformations a process to experience in person.

It endorses a set of technical skills to translate a vision into a representable and viable practice.

It challenges the existent, questions reality, nurtures doubts and reinvents cognitive paths along the way.

It launches "new images" into the public arena.

As omen, a clue of possible shifts, it evokes and sometimes encounters the novelty.

It renovates cultural schemes.

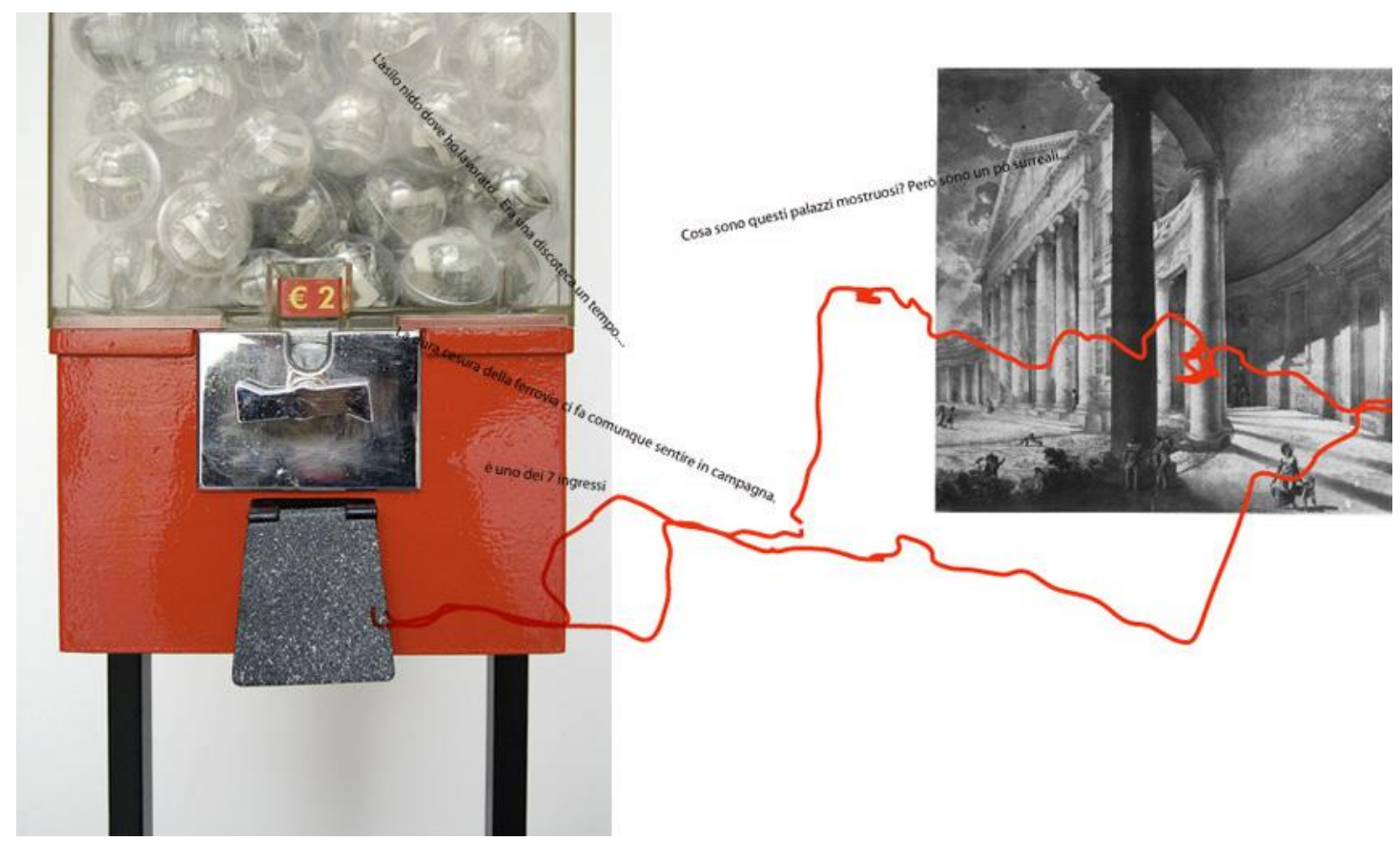

Re:bus mapping. Diego Segatto for Re:Habitat, Bologna 2011.

An explorative game playing with interviews and movements in the city, aiming to build an anti-map. It was conceived through walks, relations and instant inventiveness, deconstructing how territory is normally read. The audience and the public were participants and process facilitators, not statistical subjects. 
Antigone says: ${ }^{1}$

"Contemporaneity has produced some good outcomes since the Geneva Convention, legislative tools conceived to protect refugees, although these tools are no longer moving with the times. Contemporaneity also provokes displacements on an ever larger scale that are in many cases planned, on the basis of expectations projected toward new destinations, initiated in the countries of origin. For example the Albanians during the '80s and '90s were very much influenced by the Italian music Festival of Sanremo, thinking that the TV programme broadcasted the representation of what Italy was. Or, rather it is the creation of false myths through social media: people coming from the Sub-Saharan area arrive with a huge amount of information, from word-of-mouth, from websites, from social networks. This of course makes things easier but often also complicates, because they arrive with a preconceived framework that collapses at the moment of landing. They find themselves in a completely different situation from what they imagined. All this is reinforced many times by those who, after a successful inclusion (in the country of arrival), tend to give a sugarcoated version of their experience (to the country of departure). This is, I think, very different from the past: the creation of myths and expectations that are doomed to be disappointing for most."

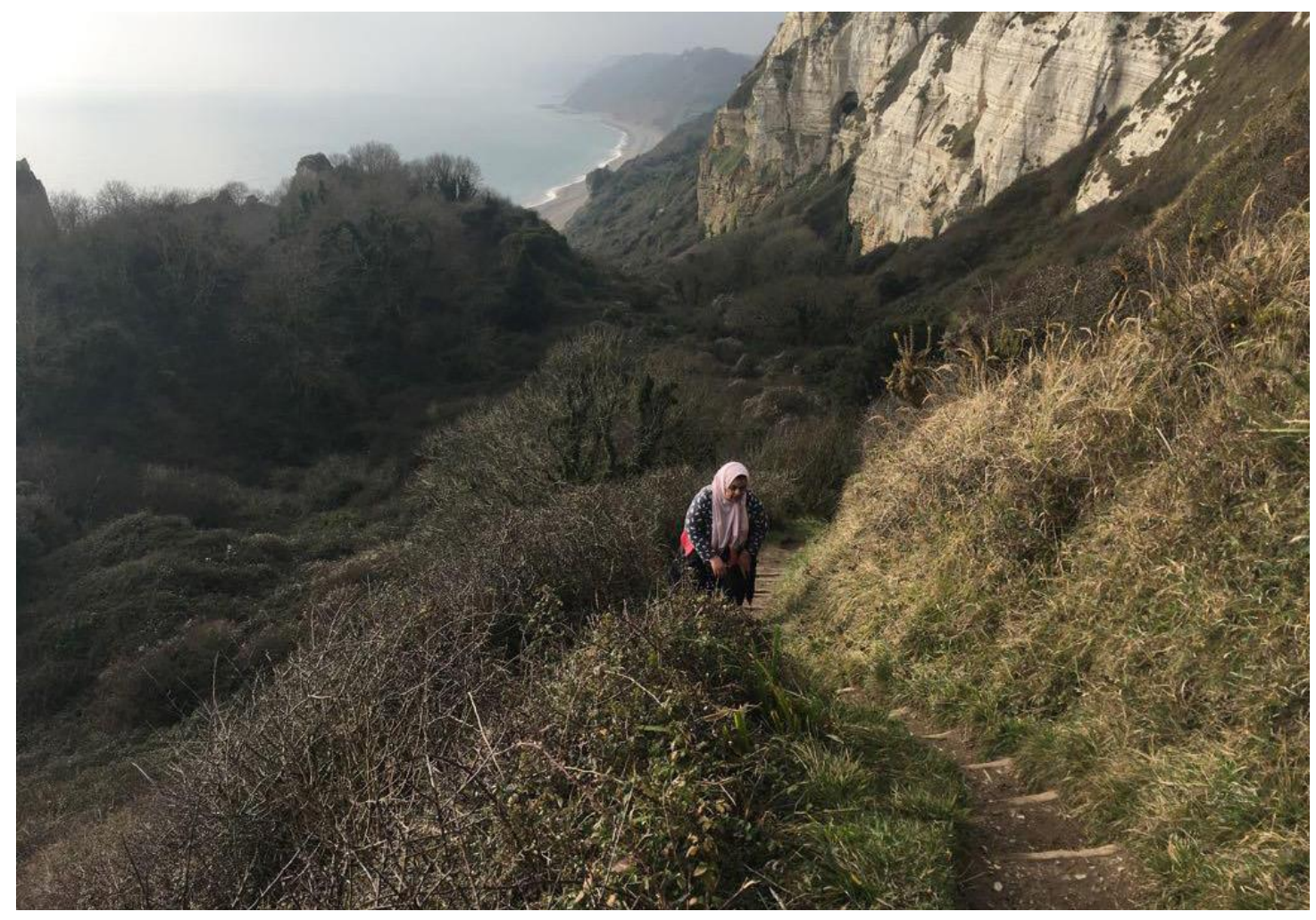

A journey to Xeniwhere, Branscombe to Beer, UK, 2017, ph: Elena Isayev. A work-group of students, with Campus in Camps programme coordinators, produced a Collective Dictionary as part of Ancient Journeys and Migrants, convened by Elena Isayev (University of Exeter). On behalf of Campus in Camps.

1 Excerpt of an interview with a policy advisor of a humanitarian NGO, under the guise of Antigone. For the Collective Dictionary Xenia: http://www.campusincamps.ps/projects/xenia/. 
At times, a different kind of necessity, intuition or imagination re-positions people around the globe. What was the role of the imagination when tales, spread by the roaming story-tellers, forged ideas of the world? Or what about the fantastical medieval maps, full of symbolic references? ${ }^{2}$

I'm led to believe that, once upon a time, as much as nowadays, those who move or are displaced from their land are led, in turn, to activate sooner or later an imagination that is beyond the necessities of migration and flight.

Rather than to be constrained, imagination and survival are dimensions to be met, digested and integrated.

Free thinking, escape-they can hardly be governed in the long term.
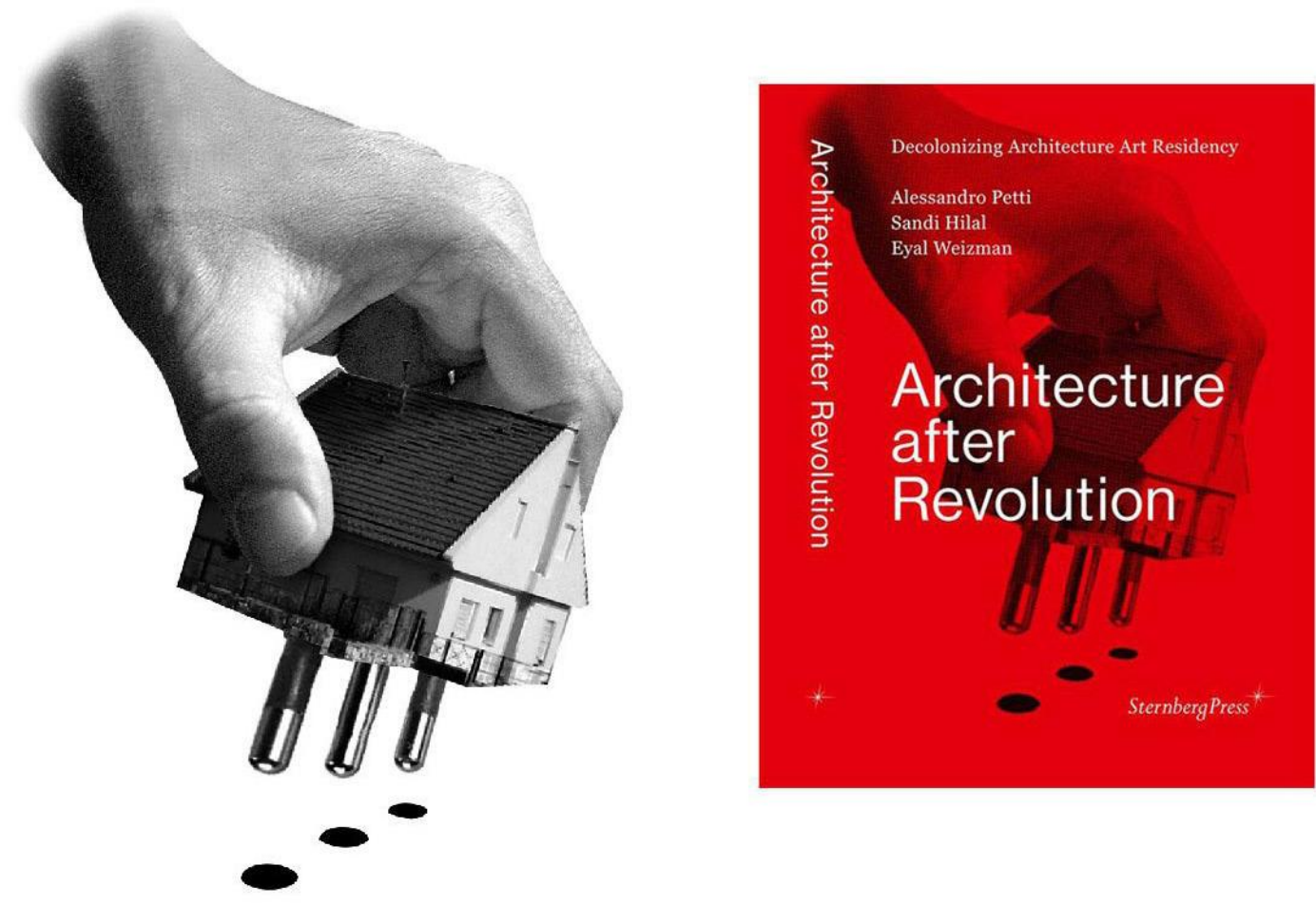

Power Unplugged, cover design for Architecture after Revolution (A. Petti, S. Hilal, E. Weizmann-Sternberg Press), Diego Segatto, Beit Sahour, Palestine, 2013. What would happen to the Israeli infrastructure of oppression if its military and civic power were to be unplugged?

Does the historian or the archaeologist-beyond the necessary preparation, competence, determination and method-need imagination to reconstruct the remains of those traces, the habits, the manufacturing, the thinking that is no longer present?

"The past is another country", some say.

Are similar wide ranging imaginative capabilities required to investigate dark matter, quantum mechanics and the varied theories of the universe?

There is no perfect formula, yet, which unveils the secrets of life and the logic of existence.

The unconceived, approached with varied dilemmas and creative responses, is experimented with using available tools to close in on the most plausible hypothesis.

2 http://www.press.uchicago.edu/books/HOC/HOC_V1/HOC_VOLUME1_chapter18.pdf. 


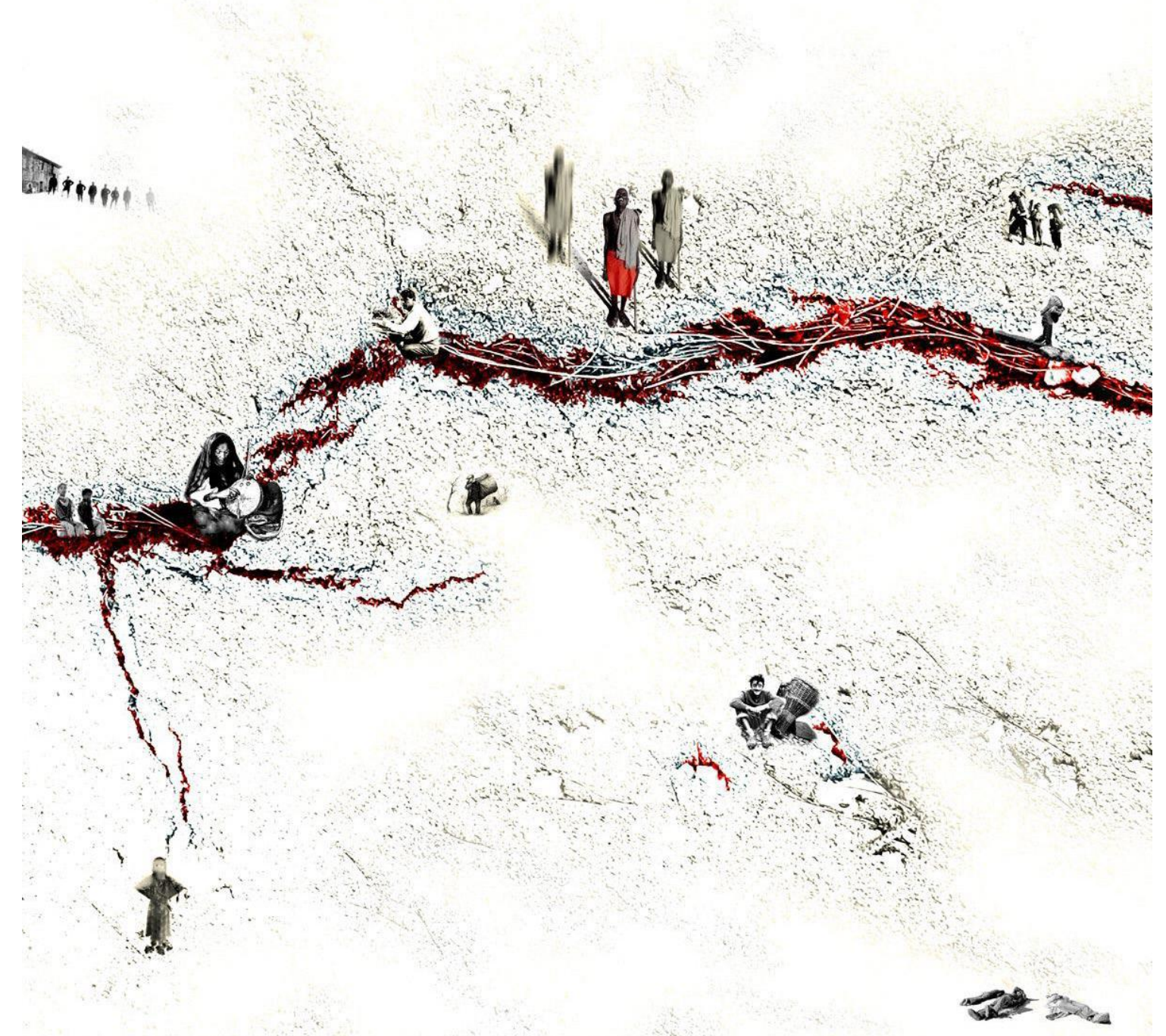

Dis Land, digital artwork and printed on canvas $90 \times 90 \mathrm{~cm}$, Diego Segatto, 2009. A visual journey, as a tribute to the first artists of displacement: travelers, migrants, refugees, gypsies, nomads and smugglers.

Living organisms, surrounded and driven by diverse quandaries and levels of response, employ the imagination to discover reality and implement its potential through accidental encounters.

They move through exploratory quests.

Awareness, creativeness, inter-disciplinarity, imagination. These engines drive mankind in formulating the "next step".

They swing between the impulse for re-invention and the need for a replicable scheme. 


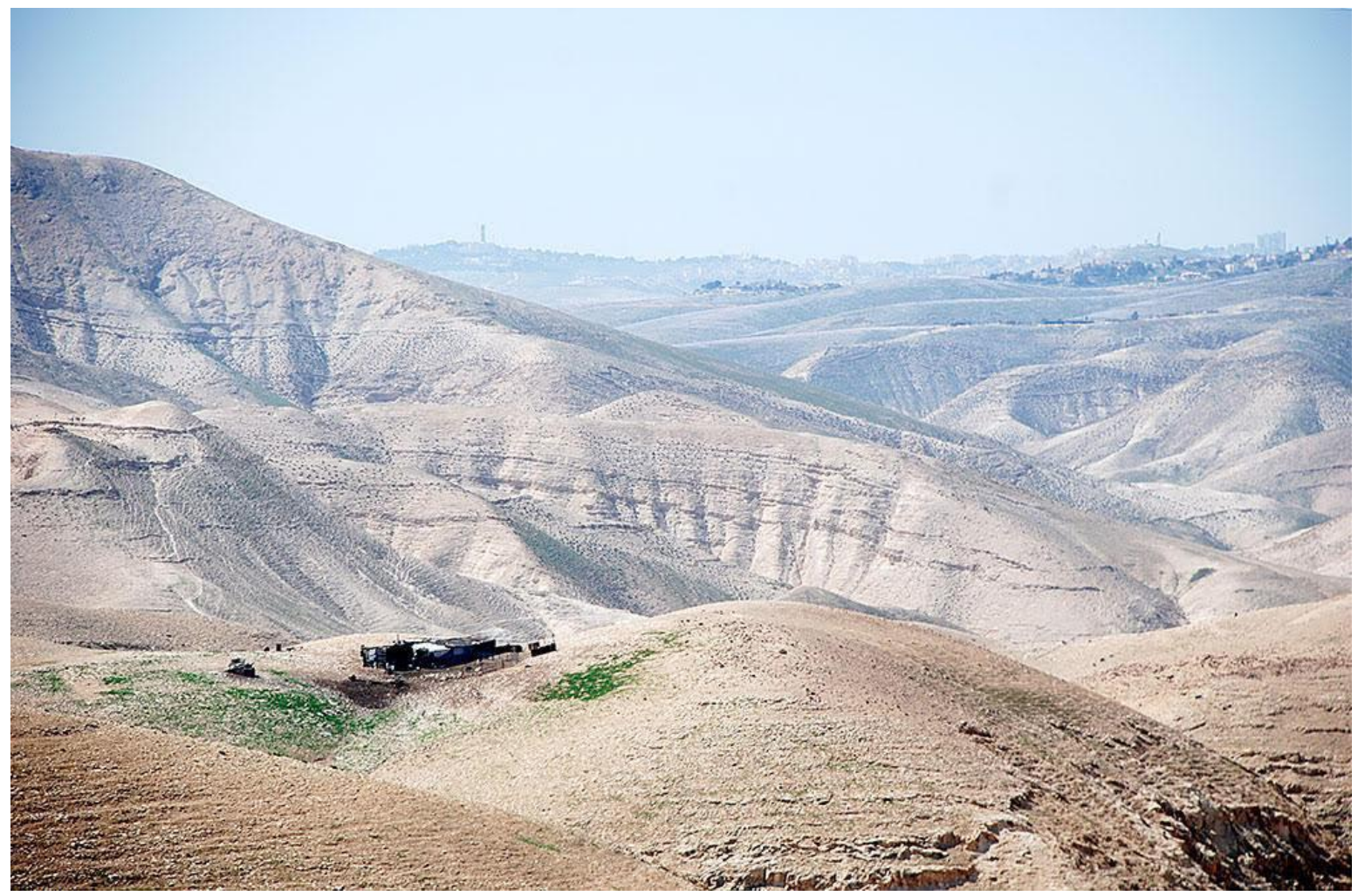

Ghorfat Al Maieshah first flag: Falastin, Wadi Al Qelt, Palestine, 2012, ph: Diego Segatto. A temporary land where disbelief is suspended instead of rights. It is symbolically defined through natural and architectural elements found on site, indoors or outdoors, and delineated in time-subject to an expiry date. Its flag is a curtain portraying a landscape, changing cyclically. Its site of discourse is a particular living-room, where people interested in a dialogue that critically and creatively confronts the issues of hospitality, communal learning and the nation-state assemble. First stop: Sardinia, Italy, 15th-28th August 2017.

Conflicts of Interest: The author declares no conflict of interest.

(C) 2017 by the author. Licensee MDPI, Basel, Switzerland. This article is an open access article distributed under the terms and conditions of the Creative Commons Attribution (CC BY) license (http:/ / creativecommons.org/licenses/by/4.0/). 